\title{
Comparison of three response-elimination procedures following FI and VI reinforcement training in humans*
}

\author{
JEFF S. TOPPING and JAMES T. CROWE \\ Mississippi State University \\ Mississippi State, Miss. 39762
}

In the present experiment, college students were trained to press a key according to a FI or VI reinforcement schedule and were then shifted to one of three response-elimination procedures: Fixed omission training, variable omission training, or extinction training. Results indicated that both omission training procedures eliminated the keypress response significantly more efficiently than did extinction training; however, the effects of the two omission training techniques did not differ significantly from each other. In addition, the effect of the initial reinforcement training schedule was not significant, nor were there any significant interactions.

Recently much research (cf. Miller \& LeBlanc, 1972; Topping \& Larmi, 1973; Topping, Pickering, \& Jackson, 1971a, 1972; Uhl, 1973; Uhl \& Garcia, 1969; Uhl \& Sherman, 1971; Zeiler, 1971) has been conducted with infrahuman Ss in an attempt to compare the response-elimination effects of omission training (OT), in which $\mathrm{S}$ is reinforced for omitting a previously reinforced response, and extinction training (ET). Although some disagreement exists as to which of these techniques yields the more rapid response reduction, the results indicate that OT consistently produces more durable elimination effects.

Two temporal parameters are involved in the OT procedure: (1) a response-reinforcement interval, which specifies the time that each response postpones reinforcement, and (2) a reinforcement-reinforcement interval, which specifies the time between reinforcements if no responses are emitted. Although these two intervals are often equated and are not changed during the course of OT, other alternatives do exist. For example, Reuter and LeBlanc (1972) compared the response-eliminating effects of two different OT procedures in preschool children. For one group (fixed), the response-reinforcement and reinforcement-reinforcement intervals were both always $5 \mathrm{sec}$; for the other group (variable), the two intervals were always identical, but their duration was varied from reinforcement to reinforcement to produce a mean value of approximately $5 \mathrm{sec}$. Their results suggested that the fixed omission training (FOT) procedure eliminated responding more effectively than did the variable omission training (VOT) procedure.

Due to the frequent use of infrahuman $S s$ in

*Requests for reprints should be sent to Jeff S. Topping,
Drawer PF, Mississippi State University, Mississippi State, Miss. 39762 . comparisons of OT and ET, the available data (cf. Johnson, McGlynn, \& Topping, 1973) on the relative efficacy of these two response elimination techniques with human Ss is extremely sparse. Therefore, the present experiment was designed to assess the relative response-eliminating effects of FOT, VOT, and ET with college students as Ss. With regard to the Ss exposed to each of these procedures, half were initially trained to respond on a fixed-interval (FI) schedule, while the other half were trained on a variable-interval (VI) schedule. Inclusion of the latter allowed for the detection of possible interaction effects which might exist between the effects of the initial reinforcement training schedule and the response-elimination technique employed.

\section{METHOD}

Subjects

The Ss were 42 male and female undergraduate college students enrolled in introductory psychology classes at Mississippi State University. Each $S$ participated in the experiment in order to partially fulfill a course requirement.

\section{Apparatus}

A $50 \times 50 \mathrm{~cm}$ portable vertical display panel with an attached $46 \times 46 \mathrm{~cm}$ horizontal platform was located on a table in the experimental room. Two vertically arranged, four-digit Lehigh Valley counters (Model No.521-72) were mounted on the vertical panel. To the left of the top counter was a green stimulus light, and on the right was the label "positive." Only the top counter was used in the present experiment, and the bottom counter was covered with a metal plate. A standard telegraph key was mounted in the center of the horizontal panel. Electromechanical programming equipment located in an adjacent room controlled all experimental events and recorded the data.

Procedure

The experiment was conducted during one session for each $\mathrm{S}$ and consisted of three phases: (1) instructions, (2) FI or VI reinforcement training, and (3) response elimination.

\section{Instructions}

Each $\mathrm{S}$ reported individually to a waiting area, from which he was escorted to the experimental room and seated at a table. The following typewritten instructions were located on the table and were read by each $S$ : "The experiment you are about to participate in will offer you a unique opportunity to gain experimental credit hours over and above that given for participation in the experiment. The extra experimental credit will depend on your performance during the experiment. You may press the key, and if so, you may use either hand. Press the key only if you desire. A green light, located to the left of the top counter, will flash indicating that you have earned a point. At the same time, the point will be added to the total on the counter.

"Now we are about to begin. Keep in mind that the idea is to obtain as many points as possible and that the number of points you accumulate is in some way related to the telegraph key. Remember, you may press the key with either hand, but only if 
Table 1

Mean Transformed Response Rates During Response Elimination

\begin{tabular}{|c|c|c|c|c|c|c|c|c|c|c|c|}
\hline \multirow{2}{*}{$\begin{array}{c}\text { Training } \\
\text { Condition }\end{array}$} & \multirow{2}{*}{$\begin{array}{c}\text { Proce- } \\
\text { dure }\end{array}$} & \multicolumn{10}{|c|}{ Blocks } \\
\hline & & 1 & 2 & 3 & 4 & 5 & 6 & 7 & 8 & 9 & 10 \\
\hline FI & $\begin{array}{l}\text { ET } \\
\text { FOT } \\
\text { VOT }\end{array}$ & $\begin{array}{l}1.27 \\
1.04 \\
1.11\end{array}$ & $\begin{array}{r}1.05 \\
.53 \\
.74\end{array}$ & $\begin{array}{l}.55 \\
.49 \\
.08\end{array}$ & $\begin{array}{l}.45 \\
.24 \\
.01\end{array}$ & $\begin{array}{l}.66 \\
.24 \\
.05\end{array}$ & $\begin{array}{l}.40 \\
.16 \\
.09\end{array}$ & $\begin{array}{l}.64 \\
.27 \\
.01\end{array}$ & $\begin{array}{r}1.26 \\
.08 \\
.07\end{array}$ & $\begin{array}{l}.47 \\
.03 \\
.04\end{array}$ & $\begin{array}{l}.47 \\
.06 \\
.05\end{array}$ \\
\hline VI & $\begin{array}{l}\text { ET } \\
\text { FOT } \\
\text { VOT }\end{array}$ & $\begin{array}{l}.98 \\
.67 \\
.96\end{array}$ & $\begin{array}{l}.74 \\
.42 \\
.42\end{array}$ & $\begin{array}{l}.86 \\
.32 \\
.28\end{array}$ & $\begin{array}{l}.61 \\
.22 \\
.32\end{array}$ & $\begin{array}{l}.64 \\
.19 \\
.24\end{array}$ & $\begin{array}{l}.51 \\
.00 \\
.04\end{array}$ & $\begin{array}{l}.63 \\
.05 \\
.03\end{array}$ & $\begin{array}{l}.54 \\
.00 \\
.04\end{array}$ & $\begin{array}{l}.32 \\
.04 \\
.00\end{array}$ & $\begin{array}{l}.30 \\
.16 \\
.04\end{array}$ \\
\hline
\end{tabular}

you desire to press it. The more points you earn, the more experimental credit you will receive. The experimenter will come in and tell you when the experiment is over and how much extra experimental credit you have earned. Any questions?"

When questions were asked, $E$ restated the instructions or those parts of the instructions that were pertinent. In addition, $\mathrm{E}$ verbally reminded $\mathrm{S}$ to try to earn as many points as possible.

\section{VI or FI Reinforcement Training}

During this phase, half of the Ss were randomly chosen to receive reinforcement for keypressing according to a VI 8-sec schedule and the remainder were reinforced for keypressing on a FI 8-sec schedule. Reinforcement consisted of the green light flashing simultaneously with the acquisition of a point on the top counter located directly in front of S. Reinforcement training continued until visual inspection indicated that S's response rate and/or pattern had stabilized.

\section{Response Elimination}

Within each of the two reinforcement training groups, seven Ss were randomly assigned to each of the following response-elimination procedures for this $15-\mathrm{min}$ phase:

(1) Extinction training (ET). In extinction training, reinforcement no longer followed the previously reinforced keypress response. During this procedure, $\mathrm{S}$ had no opportunity to obtain additional points after the VI or FI reinforcement training.

(2) Fixed omission training (FOT). During fixed omission training, the response-reinforcement and reinforcement-reinforcement intervals were both always $8 \mathrm{sec}$. Hence, each keypress postponed reinforcement for $8 \mathrm{sec}$, while omission of a keypress for $8 \mathrm{sec}$ produced reinforcement. By not keypressing, $S$ acquired a point after each 8-sec interval.

(3) Variable omission training (VOT). In variable omission training, the response-reinforcement and reinforcement-reinforcement intervals were always the same value but the value ranged from 3 to $12 \mathrm{sec}$, with a mean of $8 \mathrm{sec}$.

\section{RESULTS}

The number of keypresses in each 30-sec interval was recorded throughout reinforcement training and response elimination. During the response elimination phase, S's response rate during each 90 -sec interval was transformed by dividing it by his stabilized response rate (i.e., mean of the last six 30 -sec periods) at the conclusion of reinforcement training. Thus, a transformed value of 1.00 indicates responding at a rate equal to that observed at the termination of reinforcement training, and a value of 0.00 indicates complete cessation of keypressing. The mean transformed response rates for each group are presented in Table 1.

A 2 (reinforcement training schedules) by 3 (response elimination procedures) by 10 (blocks) split-plot factorial analysis of variance (Kirk, 1968) was conducted on the transformed response rate data in Table 1 . This analysis revealed significant main effects for response elimination procedures $(\mathrm{F}=12.53, \mathrm{df}=2 / 36, \mathrm{p}<.01)$ and blocks $(F=13.58, \mathrm{df}=9 / 324, \mathrm{p}<.01)$. Duncan's new multiple range tests were used to identify the source of the significant response elimination procedures effect. These tests indicated that the omission training procedures (FOT and VOT) were both significantly $(p<.01)$ more effective in eliminating keypressing than was ET, although their effects did not differ significantly from each other.

\section{DISCUSSION}

The present finding that omission training eliminated responding more effectively than did extinction training in college students replicates the results of numerous previous investigations with infrahumans (Miller \& LeBlanc, 1972; Topping \& Larmi, 1973; Topping et al, 1971a, 1972; Zeiler, 1971), and also supports the outcome of an earlier investigation with college students (Johnson et al, 1973).

The fact that FOT and VOT did not differ in effectiveness in the present study disagrees with Reuter \& LeBlanc's (1972) finding that FOT was more efficient than VOT in reducing response rate. However, several differences between the two experiments precludes any direct comparisons. For example, Ss (college students vs preschool children), reinforcement training schedules (FI or VI vs VR), and the average length of response omission required to produce reinforcement $(8 \mathrm{vs} 5 \mathrm{sec})$ varied between the two investigations.

Topping et al (1971b) found that the effectiveness of several omission training procedures with different parameters did not interact with the type of prior reinforcement training (FI or VI), and the lack of a significant reinforcement training effect or interaction effect in the present results replicates this previous finding.

Because of the relevance of data on response elimination for the modification of human behavior, the present authors feel that numerous parametric and replicatory investigations need to be conducted in this area using humans as Ss.

\section{REFERENCES}

Johnson, D. L., McGlynn, F. D., \& Topping, J. S. The relative efficiency of four response-elimination techniques following variable-ratio reinforcement training. The Psychological Record, 1973, 23, 203-208.

Kirk, R. E. Experimental design: Procedures for the behavioral sciences. Belmont: Wadsworth, 1968.

Miller, D. N., \& LeBlanc, J. M. Response decrement and 
resumption: A comparison of responding during and after differential reinforcement of other behavior. Paper presented at the meeting of the American Psychological Association, Honolulu, 1972.

Reuter, K. E., \& LeBlanc, J. M. Variable differential reinforcement of other behavior (VDRO): Its effectiveness as a modification procedure. Paper presented at the meeting of the American Psychological Association, Honolulu, 1972.

Topping, J. S., \& Larmi, O. K. Response elimination effectiveness of omission and two extinction training procedures. The Psychological Record, 1973, 23, 197-202.

Topping, J. S., Pickering, J. W., \& Jackson, J. A. The differential effects of omission and extinction following DRL pretraining. Psychonomic Science, 1971a, 24, 137-138.

Topping, J. S., Pickering, J. W., \& Jack son, J. A. Omission training effects following VI and FI pretraining. Psychonomic Science, 1971b, 24, 113-114.

Topping, J. S., Pickering, J. W., \& Jackson, J. A. Comparison of omission and extinction following FR reinforcement training.
The Psychological Record, 1972, 22, 221-224.

Uhl, C. N. Eliminating behavior with omission and extinction after varying amounts of training. Animal Learning \& Behavior, 1973, 1, 237-240.

Uhl, C. N., \& Garcia, E. E. Comparison of omission with extinction in response elimination in rats. Journal of Comparative \& Physiological Psychology, 1969, 69, 554-562.

Uhl, C. N., \& Sherrnan, W. O. Comparison of combinations of omission, punishment, and extinction methods in response elimination in rats. Journal of Comparative \& Physiological Psychology, 1971, 7.4, 59-65.

Zeiler, M. Eliminating behavior with reinforcement. Journal of the Experimental Analy sis of Behavior, 1971, 16, 401-405.

(Received for publication October 19, 1973.)

\section{Attitude extremity as a determinant of attitude change in the forced-compliance experiment}

\author{
DAVID R. SHAFFER* \\ University of Georgia, Athens, Ga. 30602
}

Ss, holding either extreme or moderate initial attitudes, wrote counterattitudinal essays in a test of contradictory hypotheses derived from Festinger's cognitive dissonance theory and Bem's self-perception theory. The results indicated, as predicted by dissonance theory, that Ss holding extreme initial attitudes showed more attitude change after counterattitudinal advocacy than Ss holding moderate initial attitudes. It was demonstrated that the results were not due to regression effects, to the production of differentially persuasive essays across the extremity conditions, or to the fact that Ss holding extreme attitudes had more "room for

*Requests for reprints should be addressed to David $R$. Shaffer, Department of Psychology, University of Georgia, Athens, Ga. 30602. Sponsored by Clyde Hendrick, who takes full editorial responsibility for its contents. change" in the direction of their essays than Ss holding moderate attitudes.

According to dissonance theory (Festinger, 1957; Brehm \& Cohen, 1962), a person who is induced to commit himself to an attitudinal position that is unambiguously inconsistent with his own private attitude will experience an aversive psychological tension, cognitive dissonance. The dissonance produced by a "forced-compliance" of this nature might easily be reduced if the person were simply to change his private attitude to make it consistent with his recent counterattitudinal advocation. Dissonance theory would predict that the more extreme the person's initial attitude, the greater the experience of dissonance resulting from counterattitudinal advocacy, and the greater the attitude change necessary to reduce that dissonance.

Bem $(1965,1967,1972)$ rejects the notion that an aversive mediator such as cognitive dissonance is 